\title{
SCIENTIFIC REPORTS

\section{OPEN Chemical composition, Fatty acids profile and Biological properties of Thymus capitatus (L.) Hoffmanns, essential Oil}

\author{
Amira Zaïri ${ }^{1 *}$, Sahar Nouir ${ }^{1}$, Amira Zarrouk ${ }^{1}$, Houda Haddad ${ }^{1}$, Amani Khélifa ${ }^{1}$, Lotfi Achour ${ }^{2}$, \\ Frédéric Tangy ${ }^{4}$, Maher Chaouachi ${ }^{2} \&$ Mounir Trabelsi $^{3}$
}

$T$. capitatus is widely used in traditional medicine in Tunisia. The main goal of this study was to evaluate the phytochemical composition, the fatty acids profile, the antioxidant, antibacterial, and antifungal activities as well as the cytotoxic potential of the essential oil (EO) of this plant. The identification and the quantification of the different constituents of the tested EO was determined by gas chromatography-mass spectrometry (GC-MS). Antioxidant activities were evaluated by spectrophotometric methods and chemical tests. HCT 116 cells were used to evaluate the cytotoxic effect of the EO. The microdilution method was conducted to evaluate the antibacterial activity. Poisoned food method was used to test the antifungal activities against fungi species such Aspergillus niger and Aspergillus flavus. The EO presented several components, mainly monoterpenes. Results revealed that $T$. capitatus EO is not cytotoxic and showed excellent antioxidant activity with a dose dependent manner. Regarding antimicrobial activity, $T$. capitatus EO was efficient against all tested bacteria and fungi.

Reactive Oxygen species (ROS) are considered as the most important perpetrators for the spread of multitude of health-related problems. These free radicals may initiate DNA deteriorating and oxidize various molecules such as nucleic acids and proteins ${ }^{1}$. The other concern is infections due to resistant microorganisms. Among the most serious diseases, microbial infections generated by fungal and bacterial strains have long been a topic of interest in the scientific community ${ }^{2,3}$. Thus, there's an urgent need to develop antibacterial and antifungal agents to treat fungal and bacterial infections. To overcome these opportunistic infections and these sudden outbreaks of oxidative stress, natural products from plant have been intensively explored to provide compounds against a large number of diseases associated to oxidative stress and microorganisms infections ${ }^{4}$. We are interested on the essential oils, which increasingly attract the attention of various fields. Indeed, the EOs are qualified as volatile molecules. They are considered as the products of specialized secretory structures (differentiated parenchyma cells and glandular hairs) and are synthetized via the secondary metabolism of higher plants ${ }^{5}$. These EO are characterized by several biological activities, such as antioxidant, anticonvulsant, analgesic, anxiolytic, and antimicrobial properties ${ }^{6}$.

The Lamiaceae family is widely used as a source of spices and functional ingredients ${ }^{7}$. Within this family, particular consideration was given to the genus Thymus thanks to their food-related biological properties and their aromatic composition. In Tunisia, Thymus species grow at altitudes ranging from 120 to 1100 and are distributed from the sub-humid to the lower arid bioclimates ${ }^{8}$. The pharmacological activity of Thymus EO have been evaluated, including antimicrobial properties and antioxidant activity ${ }^{9-11}$, whereas only minor studies report the bioactivities of the Tunisian T. capitatus $\mathrm{EO}$ against a large panel pathogens including bacteria and fungi. As far as we know no data are available in its cytotoxicity. Accordingly, the purpose of the present work was to evaluate, for

\footnotetext{
${ }^{1}$ Laboratory of Biochemistry, Faculty of Medicine, University of Sousse Tunisia, 4002, Sousse, Tunisia. ${ }^{2}$ Laboratory BIOVAL, High Institute of Biotechnology, University of Monastir, 5000, Monastir, Tunisia. ${ }^{3}$ Laboratory of cytogenetic, Molecular Biology and Biology of Reproduction; Faculty of Medicine Sousse, University of Sousse Tunisia, 4002, Sousse, Tunisia. ${ }^{4}$ Department of Virology, Viral Genomics Unit and Vaccination, Pasteur institute Paris, Paris, France. *email: zairi_amira@yahoo.fr
} 


\begin{tabular}{|l|l|l|l|}
\hline \multirow{2}{*}{ Collection site } & \multicolumn{3}{|l|}{ Geographical Location } \\
\cline { 2 - 4 } & Longitude (N) & Latitude (E) & Altitude (m) \\
\hline Kairouan & $36^{\circ} 33^{\prime} 84^{\prime \prime}$ & $10^{\circ} 51^{\prime \prime} 52^{\prime \prime}$ & 57.6 \\
\hline
\end{tabular}

Table 1. Collection site of cultivated Thymus capitatus and its eco-geographical characteristics.

the first time, the chemical profile of T. capitatus EO, (i) its antimicrobial properties (ii) its safety by determining its cytotoxic properties iii) and its fatty acids profile.

\section{Material and Methods}

Plant material. The Aerial parts of investigated T. capitatus (leaves) samples were gathered at the complete flowering stage in February and March 2016 from Kairouan, Tunisia (Table 1). The taxonomic identification is authenticated by Ms. Hamdi LAZHAR, the forest engineer of Bouhedma Natural Park, and plant voucher specimens were placed at the 3 herbarium of the Laboratory of Medicinal Plants (INAT). Leaves separated from branches are dehydrated at room temperature for 7 days and slightly blended into fine powders for extractions.

The essential oil extraction. Hydro-distillation was used to extract EO from the dried aerial parts of $T$. capitatus. Thus, an apparatus of Clevenger type was used. In brief, the extraction was conducted for $3 \mathrm{~h}$ by mixing $100 \mathrm{~g}$ of plants in $500 \mathrm{~mL}$ of distilled water. The extract was dried and concentrated using sodium sulphate and rotatory evaporator under reduced pressure. The EO yield was established by quantity of the obtained oil in $\mathrm{mL}$ for $100 \mathrm{~g}$ of dried plant. Finally, the pure EO was stored at $-4^{\circ} \mathrm{C}$ until further analyzed.

Essential oil analysis. The chemical composition of EO was examined by GC and GC-MS. GC analysis was conducted using a Varian Hp-5890 gas chromatograph equipped with HP5 and Innovax $(30 \mathrm{~m} \times 0.25 \mathrm{~mm}$, film thickness $0.25 \mu \mathrm{m}$ ) bonded silica capillary columns and a FID. The temperatures of the injector and detector were $240^{\circ} \mathrm{C}$ and $280^{\circ} \mathrm{C}$, respectively. The oven temperature program was $50^{\circ} \mathrm{C}$ for $3 \mathrm{~min}$, and then $50-280^{\circ} \mathrm{C}$ at $9^{\circ} \mathrm{C} / \mathrm{min}$ and maintained at $280^{\circ} \mathrm{C}$ for $3 \mathrm{~min}$. the carrier gas was nitrogen at a flow rate of $1 \mathrm{ml} / \mathrm{min}$. a volume $(0.1 \mu \mathrm{l})$ of the diluted sample was injected. The proportion of the constituents was determined by the integration of peak areas.

In addition, a HP 5972/A MS was used to analyze the EO by operating at $70 \mathrm{eV}$ in the same conditions as described above, using the helium at 20 p.s.i. as a carrier gas. The identification of the different compounds was defined by comparison of their retention indexes (determined relatively to the retention times of a series of $\mathrm{n}$-alkanes) with those of standards of the Wiley library search routines ${ }^{12}$, based on fit and purity of mass spectra.

Cytotoxic activity of extracts. The potential cytotoxicity of T. capitatus EO was carried out by the MTT based assay and measured in human colon cancer cell line HCT116. In brief, cells were seeded at a density of $5 \times 10^{3}$ per well and were seeded overnight at $37^{\circ} \mathrm{C}$. The culture medium was removed and cells were treated with the $\mathrm{EO}$ at concentration ranging from 0 to $2 \mathrm{mg} / \mathrm{ml}$. DMSO was used to dissolve the EO. Further dilution was conducted to reach the desired final concentration. Each concentration was tested in triplicate. After incubation ( $30 \mathrm{~min}, 3 \mathrm{~h}$, or $6 \mathrm{~h})$, cells were treated with MTT solution $(5 \mu \mathrm{g} / \mathrm{ml}$ in culture medium). To dissolve the dark blue formazan crystals formed by the tetrazolium-formazan reaction, solubilization buffer was added to each well. OD was measured at $595 \mathrm{~nm}$ after overnight incubation at $37^{\circ} \mathrm{C}$. The ratio; OD in the test group/OD in the control group) $\times 100$ was calculated to express the percentage of cell survival.

DPPH Radical scavenging activity. The T. capitatus EO antioxidant activity was performed by means of the stable DPPH on the basis of a modified method, reported by Kartal et al. ${ }^{13}$. Upon its reduction by an antiradical compound, DPPH loose its absorption band at $517 \mathrm{~nm}$. Briefly $180 \mu \mathrm{l}$ of different concentrations of EO $(0.009-0.312 \mu \mathrm{g} /$ $\mathrm{ml}$ ) was added to $1620 \mu \mathrm{l}$ of DPPH, prepared daily. The absorbance was calculated at $517 \mathrm{~nm}$ and corresponded to the ability of extract to reduce the DPPH to the yellow-colored diphenylpicrylhydrazine. The ascorbic acid was used as a reference. The antioxidant activity was expressed as $\mathrm{IC}_{50}$. A higher antiradical activity of EO corresponds to a lower $\mathrm{IC}_{50}$ value. This activity was measured using the following equation: $\%$ inhibition $=\left[\left(\mathrm{A}_{0}-\mathrm{A}_{1}\right)\right] / \mathrm{A}_{0} \times 100$.

Antibacterial activity. Strains used in this work were identified and provided by the department of Clinical Microbiology, Faculty of Medicine of Sousse, Tunisia and were resistant to several conventional antibiotics. They were preserved as follows: S. typhimurium was grown in LB medium, E. coli, S. aureus and S. epidermis were grown in $\mathrm{MH}$ broth. The antibacterial activity of EO sample was performed using the MIC determination method as it was described by Zaïri et al. ${ }^{14}$. Briefly, planktonic growths of different strains were tested in the absence and presence of a sample at different concentrations. After an overnight culture, $100 \mu \mathrm{l}$ of sterile medium were inoculated by each bacterial strain in a 96 -well plate to $\mathrm{OD}_{600}=0.0001$. The samples were used to final concentrations ranging from 0 to $1 \mathrm{mg} / \mathrm{ml}$. Polymyxin $(6.25 \mu \mathrm{g} / \mathrm{ml})$ was used as a positive control. Control wells were prepared were with plant extracts only. Each test was performed in triplicate. Cultures were then incubated with shaking at $37^{\circ} \mathrm{C}$ for $24 \mathrm{~h}$. The lowest concentrations that induced $100 \%$ inhibition was used to determine MIC values ${ }^{14}$.

Antifungal activity. The T. capitatus $\mathrm{EO}$ was evaluated fort its antifungal activity against Aspergillus niger and Aspergillus flavus using a Poisoned food technique as it was described by Kumar et al. ${ }^{15}$. Briefly $20 \mu \mathrm{l}$ of oil sample were added to $10 \mathrm{ml}$ to tepid Potato Dextrose Agar (PDA) medium at appropriate concentrations. Each medium was separately poured into petriplates. At the centre of the Petri dishes were added $5 \mathrm{~mm}$ disc of seven day old culture of the Aspergillus niger and Aspergillus flavus. The plates were incubated at $25 \pm 1{ }^{\circ} \mathrm{C}$ for seven days. The Petri dishes containing same amount of distilled water and media free from the extract served as control. After incubation, the colony diameter was measured in $\mathrm{mm}$. For each, experiment was performed three times. 


\begin{tabular}{|c|c|c|c|}
\hline No & RI & Compound & $\%$ \\
\hline 1 & 935 & $\alpha$-Thujene & 0.54 \\
\hline 2 & 940 & $\alpha$-Pinene & 0.38 \\
\hline 3 & 991 & Myrcene & 0.87 \\
\hline 4 & 1019 & 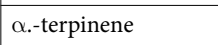 & 1.11 \\
\hline 5 & 1025 & p-Cymene & 6.25 \\
\hline 6 & 1063 & $\gamma$-Terpinene & 6.75 \\
\hline 7 & 1089 & $\alpha$-terpinolene & 0.26 \\
\hline 8 & 1101 & Linalool & 1.51 \\
\hline 9 & 1179 & Terpinen-4-ol & 1.40 \\
\hline 10 & 1185 & 4-Carvomenthenol & 0.94 \\
\hline 11 & 1260 & Geraniol & 0.25 \\
\hline 12 & 1309 & Carvacrol & 65.38 \\
\hline 13 & 1310 & Thymol & 1.35 \\
\hline 14 & 1358 & Eugenol & 0.21 \\
\hline 15 & 1408 & Carvacryl Acetate & 0.45 \\
\hline 16 & 1427 & $\beta$-Caryophyllene & 4.94 \\
\hline 17 & 1461 & $\alpha$-Humulene & 0.10 \\
\hline 18 & 1487 & allo-aromadendrene & 0.18 \\
\hline 19 & 1685 & $\alpha$-Bisabolol & 0.35 \\
\hline 20 & 1774 & $\alpha$-Bisabolol oxide $\mathrm{A}$ & 0.11 \\
\hline 21 & 1815 & Hexadecanal & 0.14 \\
\hline 22 & 1870 & 1-Hexadecanol & 0.46 \\
\hline 23 & 1879 & 1-Hexadecanol & 0.13 \\
\hline 24 & 1894 & Rimuene & 0.28 \\
\hline \multirow[t]{3}{*}{25} & 1957 & Hexadecanoic acid & 0.68 \\
\hline & & Total identified & 95.02 \\
\hline & & Unknown & 4.98 \\
\hline
\end{tabular}

Table 2. Chemical composition of T. capitatus EO.

The percentage of mycelial growth inhibition was calculated using the formula: Antifungal index $=(1-\mathrm{Da} /$ $\mathrm{Db}) \times 100$.

Fatty acids analysis. Total lipids were extracted from the EO according to the method of Moilanen and Nikkari ${ }^{16}$. Boron trifluoride in methanol $(14 \%)$ was used to transmethylate lipids. Hexane was used to extract the fatty acid methyl esters, which were analyzed by Gas Chromatography (GC) on a Hewlett Packard Model 5890 gas chromatograph (Palo Alto, CA, USA) equipped with a flame ionization detector and a CPSIL- 88 column $(100 \mathrm{~m} \times 0.25 \mathrm{~mm}$ i.d., film thickness $0.20 \mathrm{~mm}$; Varian, Les Ulis, France). The carrier gas was Hydrogen. The oven temperature program was as follows; $60^{\circ} \mathrm{C}$ for $5 \mathrm{~min}$, enhanced to $165^{\circ} \mathrm{C}$ at $15^{\circ} \mathrm{C} / \mathrm{min}$ and maintained for $1 \mathrm{~min}$, and then increased to $225^{\circ} \mathrm{C}$ at $2{ }^{\circ} \mathrm{C} / \mathrm{min}$ and then maintained at $225^{\circ} \mathrm{C}$ for $17 \mathrm{~min}$. The injector and the detector temperature was detained at $250^{\circ} \mathrm{C}$. Fatty acid were recognized by comparison with synthetic standards. The data were expressed as $\mathrm{mg} / 100 \mathrm{~g}$ of oil. This experiment was performed in triplicate.

Statistical analysis. The statistical analysis was conducted using Statistical Package for the Social Science (SPSS) version 22. The Mann-Whitney U test was used in these analyses. Data were considered statistically different at a P-value of 0.05 or less.

Ethical approval and informed consent. In this manuscript no experiments were carried out on (i) live vertebrates (or higher invertebrates), (ii) humans or (iii) human samples.

\section{Results and Discussion}

Essential oil analysis. The essential oil yield of T. capitatus was $0.82 \%$. Its chemical composition has been identified and quantified based on GC-MS. Overall, 25 components were identified, including sesquiterpenes, monoterpenes, and other compounds like, organic acids alcohols and phenols (Table 2, Fig. 1). Hydrocarbons and oxygenated monoterpenes were the predominant classes, while sesquiterpenes and other classes were the least characterized. We noted that the oxygenated monoterpene carvacrol $(65.38 \%)$ greatly characterizes the $T$. capitatus EO being its main constituent. Our results are in concordance with previous study on the EO of T. capitatus grown in Tunisia, where carvacrol (68.5\%), were identified as the major constituent. They also showed that this oil was characterized by the presence of $p$-cymene, $\gamma$-terpinene and $\beta$-caryophyllene ${ }^{17,18}$. The high carvacrol content is associated with the dry dwarf-shrub formations of the lowland ${ }^{19}$, and that the content of sesquiterpenes such as b-caryophyllene decreases with increasing altitude ${ }^{19}$. However, reports on different regions of North

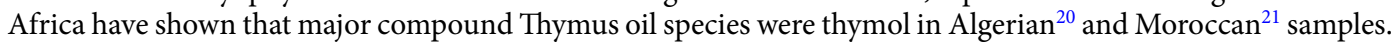
Worldwidely, our results are partly in agreement with a recent published report by Gonçalves and co-workers 


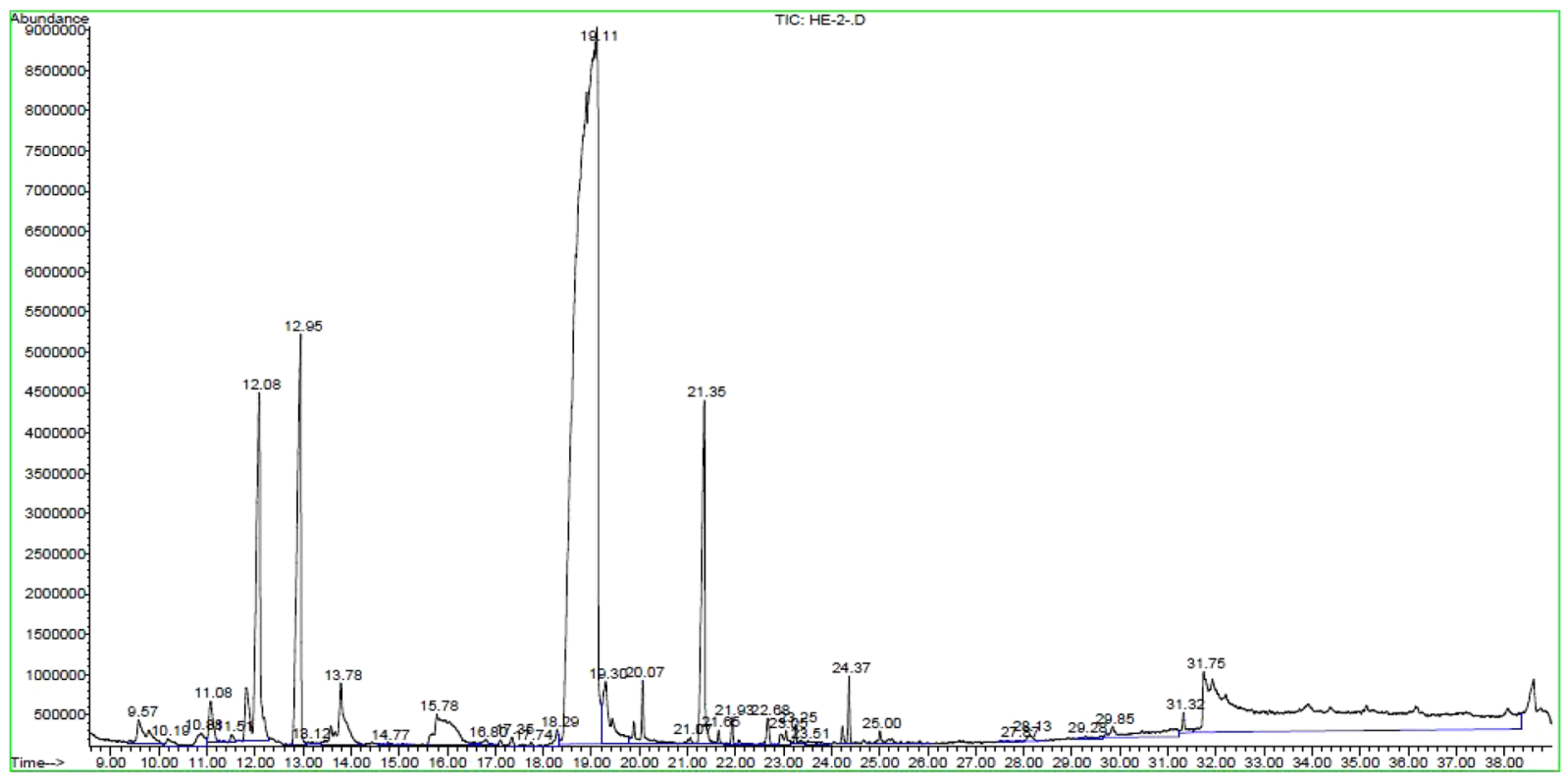

Figure 1. Chromatogram of T. capitatus EO.

\begin{tabular}{|l|l|l|}
\hline & Cytotoxicity $\mathbf{C C}_{\mathbf{5 0}}(\boldsymbol{\mu g} / \mathbf{m l})$ & DPPH IC $_{50}$ \\
\cline { 1 - 1 } Essential Oil & \multirow{2}{*}{$1482.95 \pm 170.98$} & $0.080 \pm 0$ \\
\cline { 1 - 2 } T. capitatus & & \\
\hline
\end{tabular}

Table 3. Antioxidant assays ( $\mathrm{IC}_{50}$ values) and Cytotoxicity of T. capitatus essential oil on HCT-116 (CC ${ }_{50}$ values). Data are means $\pm \mathrm{SD}$ of three independent experiments.

on T. capitatus EO grown in Sicily who revealed the predominance of oxygenated monoterpens carvacrol (80\%) as a major component ${ }^{22}$. Again, according to the literature, the composition of these EOs might be influenced by various factors. The most important are the climate, the soil, and the method of preservation and extraction. Genetic factors, vegetative cycle, altitude as well as the phonological stage can also influence this variability and this certainly contributed to produce a spectacular chemical composition of the oils. It is worth noting that the composition of these volatile oils varies according to the countries, or the places in the same country ${ }^{23}$.

In vitro toxicity of extracts against human cells. As far as we know, few reports are available on cytotoxicity of a plant extracts before proceeding to their biological activities. Our results revealed that, even when used at high concentrations, T. capitatus EO is not toxic (Table 3). According to the literature, plants extracts with $\mathrm{LC}_{50} \leq 20 \mathrm{~g} / \mathrm{ml}$ are considered toxic, we can therefore conclude that our extract remains nontoxic ${ }^{24}$. Plants extracts that are toxic to the cells rather than to pathogens, may present no therapeutic value or use. In vivo toxicity assays should be tested before a definitive conclusion can be approved. Some studies have reported that the high cytotoxic activity of EO could be mainly attributed to, $\alpha$-pinene, borneol and $\beta$-caryophyllene ${ }^{25}$. Consequently, $T$. capitatus $\mathrm{EO}$ is less cytotoxic since these compounds were not characterized as its dominant constituents.

Antioxidant activity. T. capitatus EO showed a strong radical scavenging effect, with an $\mathrm{IC}_{50}=0.08 \mathrm{mg} / \mathrm{mL}$ (Table 3). Our results suggest also that this activity is significantly higher than those of the same local plants. For example, T. capitatus collected from Ras jdir (Tunisia) displayed antioxidant activity at $\mathrm{IC}_{50}=340 \mu \mathrm{g} / \mathrm{ml}^{25}$, whereas less than $100 \mu \mathrm{g} / \mathrm{ml}$ of our extracts was enough to reach the same effect. Furthermore, previous studies showed that several other T. capitatus EO isolated from different countries have been investigated for their antioxidant activity. For example, Tabti and his workers revealed that algerian T. capitatus EO had a noticeable antioxidant effect with an $\mathrm{IC}_{50}$ value of $102 \mu \mathrm{g} / \mathrm{mL}^{26}$. However, Dzami and co-workers showed T. capitatus EO cultivated in had a potent antioxidant activity with $\mathrm{IC}_{50}=119 \mu \mathrm{g} \mathrm{ml}^{-110}$. However, none of these studies have showed the safety or the antimicrobial effect of the EO.

Several studies showed that the antioxidant activity could be due to the presence of compounds such as monoterpenes, and oxygenated monoterpenes among them alcohols and phenols. They revealed that phenols and especially carvacrol were confirmed to posses the highest antioxidant activity ${ }^{27,28}$. Our data in antioxidant activity is in the same line with these findings since the percentage of carvacrol, which is a monoterpene phenol, were significantly high (65.38\%) in our T. capitatus EO. Thus, the observed antioxidant activity might be attributed to this compound and to several other components of essential oils, including $\alpha$-terpinene and $\gamma$-Terpinene $e^{25}$. However, non-phenolic terpenoids were also reported to have substantial antioxidant potential. In fact, Ruberto 


\begin{tabular}{|l|l|l|l|l|l|l|}
\hline \multirow{2}{*}{ Essential Oil } & \multicolumn{4}{|c|}{ Concentration (MIC) in mg/ml of EO } & \multicolumn{2}{l|}{$\begin{array}{l}\text { Percentage of mycelial growth } \\
\text { inhibition }\end{array}$} \\
\cline { 2 - 8 } & EC & ST & SE & SA & A. niger & A.flavus \\
\hline T. capitatus & $0.25^{\mathrm{a}}$ & $0.12^{\mathrm{b}}$ & $0.25^{\mathrm{a}}$ & $0.12^{\mathrm{b}}$ & $32,67 \pm 3,06^{\mathrm{b}}$ & $73.33 \pm 5.79^{\mathrm{a}}$ \\
\hline
\end{tabular}

Table 4. Antibacterial and antifungal activities of T. capitatus EO. Value given as $\mathrm{mg} / \mathrm{ml}$. Data are means $\pm \mathrm{SD}$ of three independent experiments. The values with different superscript letters show significantly $(\mathrm{p}<0.05)$ different means. EC: Escherichia Coli; ST: Staphylococcus typhimurium; SE: Staphylococcus epidermis; SA: Staphylococcus aureus; A. flavus: Aspergillus flavus; A. niger: Aspergillus. Niger.

\begin{tabular}{|l|l|}
\hline Fatty acids & g/Kg of essential oil \\
\hline ESFA & 2.93 \\
\hline $12: 0$ & 0.703 \\
\hline $13: 0$ & 0.014 \\
\hline $14: 0$ & 0.100 \\
\hline $15: 0$ & 0.063 \\
\hline $16: 0$ & 1.196 \\
\hline $17: 0$ & 0.015 \\
\hline $18: 0$ & 0.822 \\
\hline $20: 0$ & 0.013 \\
\hline $22: 0$ & 0.002 \\
\hline $24: 0$ & 0.001 \\
\hline $26: 0$ & 0.003 \\
\hline$\sum M U F A$ & 0.872 \\
\hline $16: 1$ n-7 & 0.010 \\
\hline $16: 1$ n-9 & 0.012 \\
\hline $18: 1$ n-9 & 0.680 \\
\hline $18: 1$ n-7 & 0.128 \\
\hline $20: 1$ n-9 & 0.036 \\
\hline $22: 1$ n-9 & 0.007 \\
\hline$\sum$ PUFA & 0.375 \\
\hline $18: 2$ n-6 & 0.231 \\
\hline $18: 3$ n-3 & 0.094 \\
\hline $20: 2$ n-6 & 0.037 \\
\hline $22: 2$ n-6 & 0.013 \\
\hline
\end{tabular}

Table 5. Fatty acid composition of T. capitatus $E O\left(\mathrm{~g} / \mathrm{Kg}\right.$ of oil). $\sum S F A$ : Total saturated fatty acids; $\sum$ PUFA: Total polyunsaturated fatty acids; $\sum$ MUFA: Total monounsaturated fatty acids.

et al. reported that very high antioxidant activity was observed with monoterpens such as terpinolene, and to a less extent, sabinene which have camparable activity to that of $\alpha$-tocopherol ${ }^{29}$.

Antibacterial activity. To date, only few reports have been performed to determine the antibacterial activity of $T$. capitatus EO against the strains used in this study. Our results indicate that T. capitatus EO was efficient when used against all the test organisms (Table 4). Similarly, Ksouri and co-workers showed that antibacterial capacities of T. capitatus was important against E. coli and S. aureus and exceeded those of T. algeriensis ${ }^{25}$. Other studies revealed that $T$. capitatus $\mathrm{EO}$ from other countries was more active against bacterial strains. In fact, Dzamic et al. reported that the high amount of bioactive compounds in the Lybian T. capitatus EO, could explain its antibacterial activities. Accordingly, some researchers have described that there is a relationship between the antimicrobial activity and the chemical composition of the $\mathrm{EO}^{23}$. For example, the main constituents of the Thymus EOs analyzed in this work were carvacrol, linalool, and 1,8-cineol. These components could be responsible for its strong antibacterial activity in previous studies ${ }^{30}$. Our results showed also that no significant difference in susceptibility between Gram-negative bacteria and Gram-positive bacteria was found, although it was reported that the latter are less sensitive to essential oils ${ }^{10}$. This can be probably due to the fact that the hydrophobic components of EOs may inhibit the functional properties of the bacteria through the disruption of their cell membranes by separating the lipids leading ${ }^{25}$.

Antifungal activity. To the best of our knowledge, no data showed before the antifungal T. capitatus EO against A. niger and A. flavus. Interestingly, our extract was active against fungi with $73.33 \%$ mycelial growth inhibition value of $10 \mu \mathrm{l} / \mathrm{mL}$ (Table 4). Furthermore, the evaluation of Thymus EO against other fungal strains have been reported. For example, Ben jabeur et al. showed in their study that T. capitatus (chemotype carvacrol) had the highest antifungal activity followed by T. capitatus (chemotype thymol) indicating that carvacrol coud have a higher antifungal 


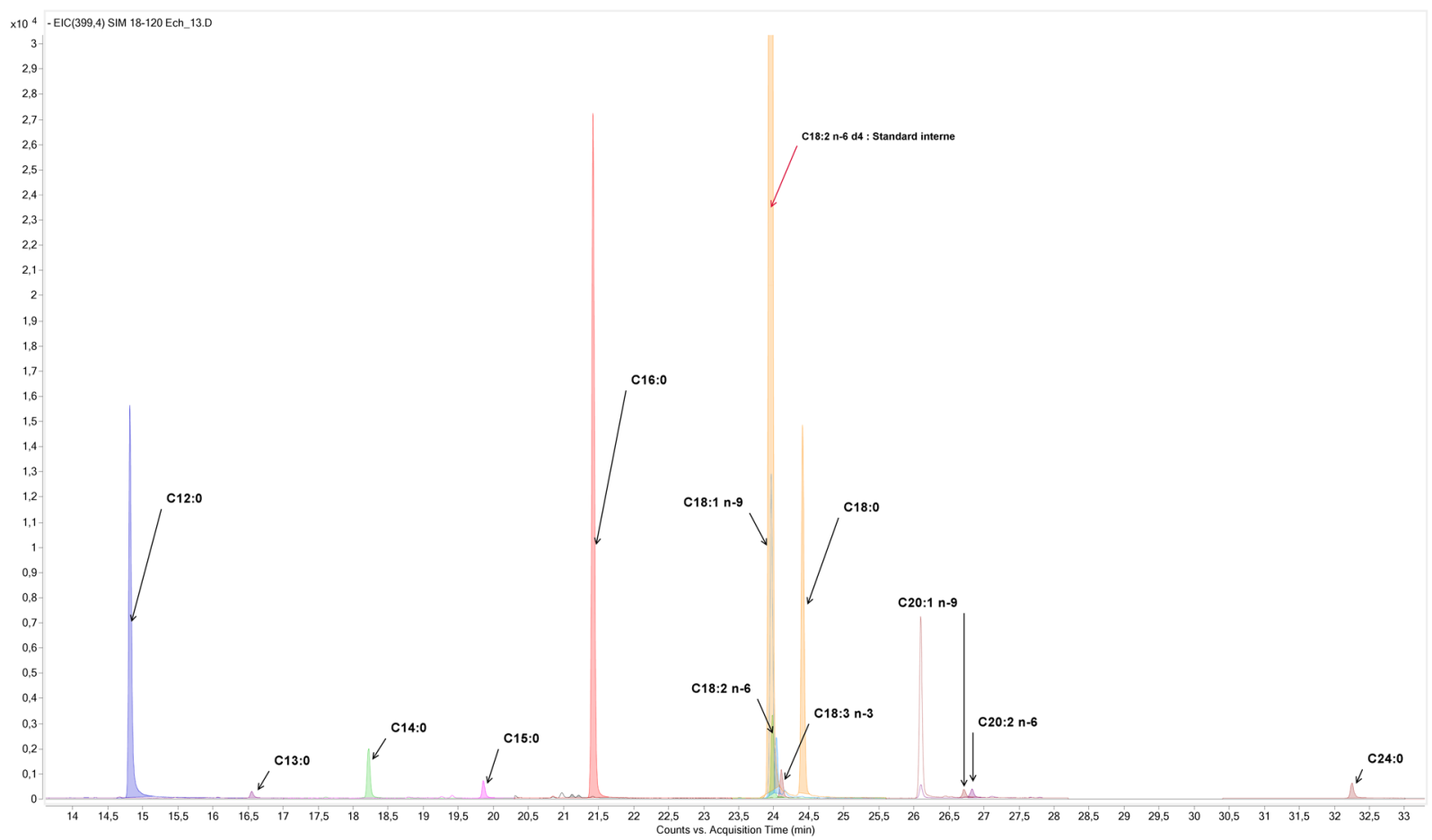

Figure 2. Fatty acids chromatogram of T. capitatus EO.

activity than thymol ${ }^{17}$. The antifungal potential of T. capitatus EO might be explained to the abundance of phenolic compounds and this result is in accordance with previous data ${ }^{30}$. Almost certainly the high amount of carvacrol in T. capitatus explains the strong antifungal activity, which approves previous reports indicating a high correlation between phenolic compounds in the EOs and the antimicrobial activity ${ }^{17}$. This activity can be also associated to the presence of minor compounds such as p_cymene and $\gamma$-terpinène. Previous reports with regard to that the analysis of the antifungal activity of EOs indicated that phenolic components may interfere with $\alpha$ and $B$-glucanases and cell wall enzymes like chitin synthase/chitinase and may attribute for the strong antifungal activity of the $\mathrm{EOs}^{10}$. Previous data indicated that antifungal effect of Thymus includes telomerase inhibition, since it enhanced the rate of apoptosis and cell senescence of Saccharomyces cerevisiae by accelerating telomere shortening ${ }^{17}$.

Fatty acids analysis. Based on our GC-MS results, where we noticed the presence of a fatty acid (Hexadecanoic acid) and on a recent study conducted by Uchenna et al., (2019) and since little is known about fatty acids profile of $\mathrm{EOs}^{31}$, it was of interest and for the first time to identify the fatty acids profile of T. capitatus essential oil in order to understand and to explain the antioxidant and the antimicrobial effects of this oil, A total of six monounsaturated fatty acids (MUFA) were identified. The major MUFA was C18:1 n-9 with $0.680 \mathrm{~g} / \mathrm{kg}$ of the essential oil, followed by C18:1 n-7 and 20:1 n-9. Total polyunsaturated fatty acids (PUFAs) accounted for $0.375 \mathrm{~g} / \mathrm{kg}$ of the essential oil, with linoleic acid (C18:2 n-6) and $\alpha$-linolenic (C18:3 n-3) being the two major PUFAs (Table 5, Fig. 2). Since LA and ALA are essential fatty acids, this oil could be considered a novel source of functional foods. These fatty acids are also the precursors of others PUFAs, known to possess a wide range of health benefits especially, eicosapentaenoic acid (C20:5n-3) and docosahexaenoic acid (DHA; C22:6 n-3) ${ }^{32}$, which could explain even in part the antioxidant effects of this oil.

\section{Conclusion}

On the basis of the results of this work, it's clearly that T. capitatus EO can be used as an easily accessible source of natural antioxidants, antimicrobials compounds and of pharmaceutical application. Devoid of toxicity and rich in phenolic compounds, T. capitatus could provide considerable benefits for health, not only in the treatment of diseases related to oxidative stress and reactive species production, but also against fungal and bacterial infections. Further analysis could be conducted to determine the whole components of T. capitatus essential oil and extracts such as the volatile fatty acid profile and/or fatty acids profile of the hexane extract and to evaluate additional biological activities of the essential oil such as the antiviral activity.

\section{Data availability}

Materials, data and associated protocols are promptly available to readers without undue qualifications in material transfer agreements.

Received: 6 May 2019; Accepted: 30 November 2019;

Published online: 27 December 2019 


\section{References}

1. Carocho, M. \& Ferreira, I. C. F. R. A review on antioxidants, prooxidants and related controversy: Natural and synthetic compounds, screening and analysis methodologies and future perspectives. Food Chemical Toxicol. 25(51), 15 (2013).

2. Mehreen, A., Waheed, M., Liaqat, I. \& Arshad, N. Phytochemical, antimicrobial and toxicological evaluation of traditional herbs used to treat sore throat. Biomed Research Int. 1-7 (2016).

3. Prakash, S. et al. In vitro scientific evaluation on antimicrobial, antioxidant, cytotoxic properties and phytochemical constituents of traditional coastal medicinal plants. Biomed Pharmacother. 83, 648-657 (2016).

4. Nieto, G. Biological activities of three essential oils of the Lamiaceae family. Medicines (Basel) 23, 1-10 (2017).

5. Lane, A., Boecklemann, A., Woronuk, G. N., Sarker, L. \& Mahmoud, S. S. A genomics resource for investigating regulation of essential oil production in Lavandula angustifolia. Planta. 231, 835-845 (2010).

6. Faturi, C. B., Leite, J. R., Alves, P. B., Canton, A. C. \& Teixeira-Silva, F. Anxiolytic-Like effect of sweet orange aroma in Wistar rats. Prog Neuropsychopharmacol Biol Psychiatry. 34, 605-609 (2010).

7. Hajlaouia, H., Mighri, H. \& Aounia, M. Screening of antibacterial, antifungal and antioxidant activities of Tunisian Thymus capitatus (L.) Hoffm. et Link essential oil. TJMPNP. 13, 20-38 (2015).

8. Miladi, H. et al. Antibiofilm formation and anti-adhesive property of three mediterranean essential oils against a foodborne pathogen Salmonella strain. Microb Pathog. 93, 22-31 (2016).

9. Mkaddem, M. G. et al. Essential oil of Thymus capitatus Hoff. et Link. from Matmata, Tunisia: gas chromatography-mass spectrometry analysis and antimicrobial and antioxidant activities. J Med Food. 13(6), 1500-4 (2010).

10. Dzamic, A. M. et al. Libyan Thymus capitatus essential oil: antioxidant, antimicrobial, cytotoxic and colon pathogen adhesioninhibition properties. J Appl Microbiol. 119, 389-399 (2015).

11. Russo, M. et al. Essential oil chemical composition and antifungal effects on Sclerotium cepivorum of Thymus capitatus wild populations from Calabria, southern Italy. Rev Bras Farmacogn. 23, 239-248 (2013).

12. Adams, R. P. Identification of Essential Oil Components by Gas Chromatography/Mass Spectrometry, 4th ed, Allured Publishing: Carol Stream, IL, USA (2007).

13. Kartal, N. et al. Investigation of the antioxidant properties of Ferula orienlis L. using a suitable extraction procedure. Food Chem. 100, 584-589 (2007).

14. Zaïri, A. et al. In Vitro Activities of Dermaseptins K4S4 and K4K20S4 against Escherichia coli, Staphylococcus aureus, and Pseudomonas aeruginosa Planktonic Growth and Biofilm Formation. Antimicrob Agents Chemother. 58(4), 2221-2228 (2014).

15. Kumar, A., Shukla, R., Singh, P., Prasad, C. S. \& Dubey, N. K. Assessment of Thymus vulgaris L. essential oil as a safe botanical preservative against post harvest fungi infestation of food commodities. Innov Food Sci Emerg. 9, 575-580 (2008).

16. Moilanen, T. \& Nikkari, T. The effect of storage on the fatty acid composition of human serum. Clin. Chimica Acta. 114, 111-116 (1981).

17. Ben Jabeur, M. \& Hamada, Wal. Antifungal activity of chemically different essential oils from wild Tunisian Thymus spp. Nat. Prod. Res. 29(9), 1-5 (2014)

18. Hedhili, L., Romdhane, M., Abderrabba, A., Planche, H. \& Cherif, I. Variability in essential oil composition of Tunisian Thymus capitatus (L.) Hoffmanns. et Link. Flavour Fragr J. 17, 26-28 (2002).

19. Karousou, R., Koureas, D. N. \& Kokkini, S. Essential oil composition is related to the natural habitats: Coridothymus capitatus and Satureja thymbra in NATURA 2000 sites of crete. Phytochemistry. 66, 2668-2673 (2005).

20. Kabouche, Z. et al. Comparative antibacterial activity of five Lamiaceae essential oils from Algeria. Int. J. Aromather. 15, 129-133 (2005).

21. Mokhtar, E. L. et al. Chemical composition and antioxidant activity of essential oils and solvent extracts of Thymus capitatus (L.) Hoffmanns and link from Morocco. J. Med. Plants. Res. 5(24), 773-778 (2011).

22. Gonçalves, J. C. et al. Essential oil composition and antinociceptive activity of Thymus capitatus. Pharm Biol. 55, 782-786 (2017).

23. Ballester-Costa, C. et al. Assessment of Antioxidant and Antibacterial Properties on Meat Homogenates of Essential Oils Obtained from Four Thymus Species Achieved from Organic Growth. Foods. 6, 59-70 (2017).

24. Zaïri, A. et al. Antioxidant, antimicrobial and the phenolic content of infusion, decoction and methanolic extracts of Thyme and Rosmarinus species. Current Pharmaceutical Biotechnology. 19(7), 590-599 (2018).

25. Meghdiche-Ksouri, W. et al. Potential use of wild Thymus algeriensis and Thymus capitatus as source of antioxidant and antimicrobial agents. J. New. Sci. 23, 1046-1056 (2015).

26. Tabti, L., El Amine Dib, M., Gaouar, N., Samira, B. \& Tabti, B. Antioxidant and Antifungal Activity of Extracts of the Aerial Parts of Thymus capitatus (L.) Hoffmanns Against Four Phytopathogenic Fungi of Citrus sinensis. Jundishapur J Nat Pharm Prod. 9(1), 49-54 (2014).

27. Skotti, E., Anastasaki, E., Kanellou, G., Polissiou, M. \& Tarantilis, P. A. Total phenolic content, antioxidant activity and toxicity of aqueous extracts from selected Greek medicinal and aromatic plants. Ind. Crops. Prod. 53, 46-54 (2014).

28. Bourgou, S. et al. Phenolic composition and biological activities of Tunisian Nigella sativa L. shoots and roots. C. R. Biol. 331, 48-55 (2008).

29. Ruberto, G. \& Baratta, M. T. Antioxidant Activity of Selected Essential Oil Components in Two Lipid Model Systems. Food Chem 69, 167-174 (2000)

30. Asres, K., Tadesse, S., Mazumder, A. \& Bucar, F. Essential oil of Plectranthus cylindraceus Hochst. Ex. Benth from Ethiopia: chemical composition and antimicrobial activity. J. Essen. Oil. Bear. Plants. 16(2), 136-43 (2013).

31. Uchenna, A. P., Charity, O. U. \& Bene, A. Properties of Oils From Plantain Pseudostem Biotransform Led Using Crude Local Enzyme Sources: A Comparison of Poultry Feed Oil. Recent Patents on Food. Recent Pat Food Nutr Agric. 10(2), 140-151 (2019).

32. Kaur, N., Chugh, V. \& Gupta Anil, K. Essential fatty acids as functional components of foods- a review. Food Sci. Tech. 51(10), 2289-2303 (2014).

\section{Author contributions}

A.Z. (Zairi) wrote the main manuscript text. S.N., H.H. and A.K. contributed to the prepared figures. A.Z. (Zarrouk) M.C. prepared figures and have made Fatty acids analysis. L.A. and F.T and M.T. have substantively revised the work

\section{Competing interests}

The authors declare no competing interests.

\section{Additional information}

Correspondence and requests for materials should be addressed to A.Z.

Reprints and permissions information is available at www.nature.com/reprints. 
Publisher's note Springer Nature remains neutral with regard to jurisdictional claims in published maps and institutional affiliations.

(c) (i) Open Access This article is licensed under a Creative Commons Attribution 4.0 International License, which permits use, sharing, adaptation, distribution and reproduction in any medium or format, as long as you give appropriate credit to the original author(s) and the source, provide a link to the Creative Commons license, and indicate if changes were made. The images or other third party material in this article are included in the article's Creative Commons license, unless indicated otherwise in a credit line to the material. If material is not included in the article's Creative Commons license and your intended use is not permitted by statutory regulation or exceeds the permitted use, you will need to obtain permission directly from the copyright holder. To view a copy of this license, visit http://creativecommons.org/licenses/by/4.0/.

(c) The Author(s) 2019 